\title{
RECENT DISSERTATIONS
}

\section{PER SUND, 2008:}

Discerning selective traditions in the socialization content of environmental education - implications for education for

sustainable development

\section{Abstract}

This thesis offers an empirical contribution to research on content issues in environmental education. One way of approaching content issues is to study the socialization content. Socialization content forms an educational context in which subject matter content can develop into meaning. Through their different actions teachers communicate companion meanings to students, which together constitute the socialization content. These are messages about the subject and about education, such as the importance of students' participation.

One important starting point for this thesis is that the learning of subject matter and socialization content is simultaneous. Learning is often regarded as an inner individual process, while socialization is more often understood as an external fostering. By using the concept of meaning making, learning and socialization can be regarded as both simultaneous and mutual.

The thesis has two main purposes, namely, methodological development and a more substantial study of socialization content. An interview method and analytical tool for researchers has been developed as a result of conducting a literature review and interviewing upper secondary school teachers involved in a general science course. This tool can be used to study the qualitative aspects of socialization content by examining shifts in five important educational aspects, and has been applied to the empirical data collected from teacher and student interviews.

The analytical tool can also be transformed into a reflection tool for teachers to render their educational habits more visible. Teachers' collective habits can develop into selective traditions in environmental education. Socialization content can be regarded as an important value-laden content that needs to be critically examined in an open democratic school system. These discussions could facilitate the development of a more pluralistic environmental education, which in turn could be further developed into an education for sustainable development.

$\begin{array}{ll}\text { Language: } & \text { Swedish summary in English } \\ \text { ISBN: } & 978-91-85485-88-8 \\ \text { Contact: } & \text { per.sund@mdh.se } \\ \text { Download: } & \text { English summary available after contact }\end{array}$

